\title{
Study of the Relationship between Emotional Attachment of Preschool Children to Parents and Their Age and Gender Identity
}

\author{
Aida Faridovna Minullina
}

IlsiyarAmirovnaAkramova

\author{
Elmira Ildusovna Murtazina
}

Kazan (Volga Region) Federal University, The Republic of Tatarstan, 420021, Kazan, M. Mejlauk Street, 1

Doi:10.5901/mjss.2015.v6n3s2p208

\begin{abstract}
The article deals with the investigation of the emotional attachment to parents of children with adequate and inadequate age and gender identity. Characteristics of the age and gender identity in children of preschool age (with adequate and inadequate age and gender identity) were established. Similar and distinctive features of the emotional attachment to parents of children with adequate and inadequate age and gender identity were revealed. We have also determined the presence and specificity of the relationship between characteristics of the emotional attachment to their parents and the age and gender identity in children of preschool age.
\end{abstract}

Keywords: pre-school children, emotional attachment, age and gender identity.

\section{Introduction}

Urgency of the research is determined by the importance of the relationship of the child with his/her adult relative for the formation of his/her personality (Vygotsky L.S., Leont'ev A.N., Rubinstein S.L., Lisina M.I.et al.) [1] This is the attachment that is a key concept describing the relationship of the child to the relative adult in modern scientific psychology [2]. Formation of this attachment is vital to the child's development. It gives him/her a sense of security, promotes the development of self-image and socialization. Selecting an object, as well as the strength and quality of the attachment is largely dependent on the behavior of parents towards the child $[3,4]$.

Various options of violations of child-parent attachment considerably affect the whole subsequent development of the child. They also have an impact on the child's relationship with the outside world, bear responsibility for the ability to form secondary attachments to friends, persons of the opposite sex, teachers and others [5]. The researchers note that the development of age and gender identity is difficult in the present conditions of our society. Many domestic and foreign scholars used to pay attention to the problem of the age and sex identification of children. Among them we can name Bazhina E., Grina R., Kagan V.E., Kohn I.S., Kohlberg L., Makobbi E. and others [6,7].

As shown by many studies, gender (sex) and age identity are the central components in the structure of the social identity of the person (Turner K.L., Brown C.S.) $[8,9]$. Gender (sexual) identity is an awareness of belonging to the male or female gender [10]. According to V.S.Mukhina, awareness of the gender identity is the sense of identity with the sex, desire to maintain the prestige of the same sex within the culture of the ethnic group [11]. Age identity is regarded by researchers as a process and result of identifying the individual of him/herself with a certain age group with adoption of the behavioral standards of the group [12]. Formation of perceptions in child about his/her age and gender roles occurs primarily in the family [13]. Researchers suggest that the leading role in the process of developing a positive sexual identity belongs to the adults who help the child to realize his/her own sexual identity and begin to consciously and unconsciously teach the sex role stereotypes to the child in accordance with masculinity and femininity accepted in a given society [14]. Thus, the family is the primary social environment for the child joining to the experience of particular society. And in this environment we can see the process of primarily formation of ideas about social groups, social roles, as well as corresponding behaviors needed for successful functioning of the individual in the society [15].

\section{Methods}

The study of the age and gender identity was performed using techniques proposed by L.N.Belopolskaya "Investigation 
of child's identity (age and gender identification)". The study of characteristics of emotional attachment to the parents of preschool children was conducted using the method "Scale of the child's attachment to their family members" by A.I.Barkan.

\section{Main Part}

The study was conducted on the basis of Municipal Autonomous Preschool Educational Institution "Kindergarten № 122" of Kazan. The subject included 50 subjects - 5-6 years old children who attended the preparatory group. As a hypothesis we made the following assumptions: 1) emotional attachment to parents of preschool children with inadequate age and gender identity is higher than in children with adequate age and gender identity; 2) high emotional attachment to the mother may contribute to the formation of inadequate age and gender identity in preschool age children. The study of age and gender identity was performed using the method proposed by L.N.Belopolskaya "Investigation of child identity (age and sex identification)" in three phases.

The task of the first phase was to assess the child's ability to identify his/her true age and gender status using the visual material presented to him/her. Based on the criterion of the correct choice of pictures (the adequacy of the age and gender identity) a group of children representing the general population was divided into two samples: the first sample children with adequate age and gender identity (group 1); the second sample - children with inadequate age and gender identity (group 2). It should be noted that most children (Group 1 - 100\%, Group 2 - 96\%) were able to identify themselves in terms of gender correctly. Consequently, exploring the phenomenon of age and gender identity (using this method), we have made an increased emphasis on the age component of the identification process.

The task of the second phase was to assess the child's ability to identify his/her past and future sex and age status presented to him/her using figurative material (Figure 1). Group $1-100.0 \%$ of the surveyed preschool children were able to identify their last image with the image of a baby shown in the image. $100.0 \%$ of the children had chosen the image of "preschooler" as "identical" character. As a "vision of the future" children chose different figures: depicting the "schoolchild" (95.7\%), depicting "boy/girl" (87.8\%), depicting "man/woman" (71.7\%), depicting "old man/old woman" (71.9\%).

Table 1. The sequence of the age and sex identification (C groups1 2)

\begin{tabular}{|c|c|c|c|c|c|c|}
\hline \multirow{2}{*}{ Groups } & \multicolumn{6}{|c|}{ Name of the cards (images) } \\
\cline { 2 - 7 } & 1-infant & 2-Preschooler & 3-Schoolchild & 4- boy/girl & 5-man/woman & 6- old man/old woman \\
\hline Group I & $100.0 \%$ & $100.0 \%$ & $95.7 \%$ & $87.8 \%$ & $71.7 \%$ & $71.9 \%$ \\
\hline Group II & $47.9 \%$ & $0 \%$ & $11.8 \%$ & $23.9 \%$ & $7.8 \%$ & $11.7 \%$ \\
\hline pemp (by Fischer) & $4.51^{* *}$ & - & $3.25^{* *}$ & $2.96^{* *}$ & $1.88^{*}$ & $1.97^{*}$ \\
\hline
\end{tabular}

Note: * - the differences were considered significant at $p<0.5$; ${ }^{\star *}$ - the differences were considered significant at $p<0.01 ; * \star *$ - the differences were considered significant at $p<0.001$.

It can be argued that in the Group 1 children significantly less than in the normal cases selected images of "boy/girl" as the "future pattern" ( $\varphi$ emp $=2.41$ at $p<0.01)$, images of "men/woman" $(\varphi$ emp $=3.56$ at $p<0.01)$, images of "the old man/old woman" $(\varphi e m p=3.56$ at $p<0.01)$.

According to the author's method (by L.N.Belopolskaya), children under the age of 5 years should be able to construct a sequence of identification "infant - preschool - schoolboy" (from the 1st to the 3rd picture) correctly, and only at the age of 7 years to make the identification sequence from infant to adult (from the 1st to the 5th image) correctly [16]. Thus, the data obtained in Group 1 are not contrary to the established norms of the age and gender identity in children.

In the group of children with inadequate age and gender identity only $47.9 \%$ of the children began the chronological sequence test from the image "infant", no child was able to correctly identify his/her true age status (status of preschool). As a future pattern $11.8 \%$ of the children chose the image "schoolchild", the image "boy/girl" - $23.9 \%$ of children, the image "man/woman" - 7.8\% of children, and the image "old man/old woman" - $11.7 \%$ of children. Thus, subjects in Group 2 (relative to the subjects of Group 1) started chronological sequence with the image "infant" $(\varphi=4.51$, $p<0.01)$ significantly rarer. They also were not able to identify their actual preschool age. They were able to make a correct chronological sequence significantly less common for the following age statuses: "schoolboy" $(\varphi=3.25, p<0.01)$, " boy" ( $\varphi=2.96, p<0.01)$, "man/woman" $(\varphi=1.88, p<0.5)$, " old man/old woman" $(\varphi=1.97, p<0.5)$.

According to L.N.Belopolskaya, children with normal mental development over than 5 years old should not make any mistakes while identifying their real age and sex status [16]. According to the hypothesis of our study we tend to 
assume that such disturbances in age identity in children of the $2^{\text {nd }}$ group are associated with the factor of family relations (in particular, with characteristics of the emotional attachment of children to their parents).

In the third phase of the study we compared the following mental images of a child: "I-real," "I-attractive" and "Iunattractive" (Table 2). As an attractive pattern children from the 1st group most often pointed at the images of youth (39.9\%), explaining their choice using the following statements: "beautiful", "strong", "I want to be an adult". Some children (19.8\%) pointed at images of schoolchildren as an attractive ones ("I want to school", "she has a beautiful skirt", "beautiful"). Children in this group considered only 2 image as being unattractive: the image of an "old age" (87.9\%) ("old", "I do not want to be old", "has no hair", "can't do anything"), the rest pointed at the image of "infancy" as unattractive (19.7\%) ("I do not like infants", "I do not want to be small").

In the group of children with inadequate age and gender identity the most attractive pattern was presented by the image of "infant" (34.7\%) ("I love infants", "when I was little, mother loved", "do not need to go anywhere"). As an unattractive pattern children pointed at the image of "old age" (63.7\%) ("old", "it is difficult to walk and work for him/her/her", "I do not want to be old", "because I will die").

Table 2. Distribution of the answers "attractive" and "unattractive" images in both groups (in \%)

\begin{tabular}{|c|c|c|c|c|c|c|c|c|c|c|c|c|}
\hline \multirow{3}{*}{ Groups } & \multicolumn{10}{|c|}{ Name of the cards (images) } \\
\cline { 2 - 16 } & 1-infants & 2-preschool & \multicolumn{1}{|c|}{ 3-schoolchild } & 4-boy/girl & 5- man/Woman & \multicolumn{3}{|c|}{ 6-old man old woman } \\
\cline { 2 - 14 } & 1 & 2 & 1 & 2 & 1 & 2 & 1 & 2 & 1 & 2 & 1 & 2 \\
\hline group1 & 14.8 & 19.7 & 7.9. & 7.7 & 19.8 & $0 \%$ & 39.9 & $0 \%$ & 11.7 & $0 \%$ & 3.8 & 87.9 \\
\hline group2 & 34.7 & 7.8 & 11,8 & $0 \%$ & 11.7 & $0 \%$ & 14.8 & $0 \%$ & 14.9 & 19.7 & 3.9 & 63.7 \\
\hline pemp & 0.75 & 0.14 & 0.14 & - & 0.2 & - & 0.97 & - & 0.11 & - & - & $1.73^{*}$ \\
\hline
\end{tabular}

Note: * - the differences were considered significant at $p<0.5$; ${ }^{*}$ - the differences were considered significant at $p<0.01$; *** - the differences were considered significant at $p<0.001$.

According to researchers, a key feature for the children of all ages with normal mental development is the tendency to choose the image of the next age role as an attractive one. This feature reflects the unconscious desire of the child to grow and develop and the willingness to adopt a new age and social role [16]. And, as seen according to the results of the study a similar pattern is typical only for the subjects from Group 1. The choice by subjects from the group 2 of the image of infancy as an attractive one may indicate a delay and violation of the natural process of their growing up and infantilization. In addition, these are the social situation of the child's experience and other relevant factors in his/her life that influence the child's preferences in the construction of age and gender sequence, as well as during the choice of attractive and unattractive images.

The study of characteristics of emotional attachment of preschool children to parents was conducted using the method "Scale of child's attachment to the members of his/her family" developed by A.I.Barkan. The average value of the election by subjects in both groups (family members) of emotional attachment, as well as the significance of differences between them (evaluated by Student t-test) are shown in Table 3.

The data presented in Table 3 shows that for the test group 1 and group 2 we can see that the mother figure is the main object of the emotional attachment. Then along with the decrease in significance we can see a father's figure, and figure of grandparents. The significance of differences between mean values of the elected subjects in both groups of objects (family members) of emotional attachment was determined using the Student t-test.

For the subjects in Group 2 (with inadequate sex and age identity) the emotional attachment to the mother was significantly greater than for the subjects in Group 1 (temp $=2.74, p<0.01)$. The emotional attachment to their father was significantly less (temp $=2.73, p<0.01$ ). No significant differences were found in relation to other objects of emotional attachment (grandparents).

Table 3. The average value of the choice of objects of emotional attachment by subjects in both groups

\begin{tabular}{|c|c|c|c|c|}
\hline & Mother & Father & Grandmother & Grandfather \\
\hline Group1 & 4.56 & 3.16 & 1,24 & 0.16 \\
\hline Group II & 5.96 & 2.12 & 096 & 0.44 \\
\hline temp & $2.74^{* *}$ & $2.73^{* *}$ & 0.61 & 1.1 \\
\hline
\end{tabular}

Note: * - the differences were considered significant at $p<0.5$; ${ }^{\star \star}$ - the differences were considered significant at $p<0.01$; ${ }^{* \star}$ the differences were considered significant at $p<0.001$. 
Thus, children with inadequate age and gender identity are more attached to their mother and to a lesser extent to their father than children with adequate age and gender identity.

Analysis of the data using Student's t-test showed that there is a considerable difference between the mean values of the election of particular member of the family as the object of emotional attachment in each group of subjects. Both for the test group 1 and for the test group 2 a similar pattern is typical. Mother is the main object of emotional attachment for the children of both groups, and the importance of father, grandmother and grandfather as objects of attachment is reduced in the proper sequence. However, in the group of children with an adequate age and gender identity the emotional attachment to their father and grandmother is higher than in children with inadequate age and gender identity.

The correlation analysis between characteristics of emotional attachment to parents and the age and gender identity of preschool children in both groups shows the presence of significant connections between the studied parameters. In Group 1 - the higher the child's emotional attachment to his/her mother is, the lower it is in relation to other objects of emotional attachment (grandparents). At the same time, the higher the attachment of children to the father is the less it is towards the grandmother. The obtained results are consistent with the previous findings and can be explained by the multiple attachment model. And the higher the children's emotional attachment to their mother and father is the more likely children will choose an image of youth as an attractive pattern. Besides, the higher the children's emotional attachment to their father and lower to grandparents is, the more children are tend to choose the image of old age as unattractive pattern. It is possible that along with participation of representatives of the older generation in the upbringing of their grandchildren, the former more tend to notice and emphasize (because of their age) the negative characteristics of the elderly people ("disease", appearance, limitation of mobility, activity).

In Group 2 we can see that the higher the emotional attachment of children with inadequate age and gender identity to the mother is, the lower it is towards other family members. The figure of the mother is the only main object of emotional attachment of children. At the same time high emotional attachment of children to the mother is associated with the fact that they tend to choose an image of infancy as an attractive pattern. In addition, the less emotionally children are attached to the grandmother, the more often they choose an image of infancy as an attractive pattern and the image of old age as an unattractive image. High emotional attachment of children to the mother possibly may contribute to the narrowing of the scope of their communication with other family members (grandparents) and leads to a deficiency of positive experience of social interaction with the older generation.

\section{Conclusion}

To date there's not enough data to clarify the issues of psychological mechanisms of the socializing influence of the family. In particular, the mechanisms of formation of social identity of the child in family socialization remains unclear. Determining the relevance of this issue allowed to formulate the purpose of this study - to identify particular characteristics of emotional attachment to parents of preschool children with adequate and inadequate age and gender identity. The article investigates the emotional attachment to parents of children with adequate and inadequate age and gender identity. We have identified the characteristics of the age and gender identity in children of preschool age (with adequate and inadequate age and gender identity). Similar and distinctive features of the emotional attachment to parents in children with adequate and inadequate age and gender identity were revealed. We determined the presence and specificity of the relationship between the characteristics of the emotional attachment to their parents and the age and gender identity in children of preschool age. The proposed hypothesis was fully confirmed in relation to the first hypothesis: the emotional attachment to parents of preschool children with inadequate age and gender identity is higher than in children with adequate age and gender identity. The assumption that high emotional attachment to the mother may contribute to the formation of inadequate age and gender identity in children of preschool age was partially confirmed.

\section{Summary}

Summarizing the resulting data at each stage of the results we made the following conclusions: 1 . Preschool children with adequate and inadequate age and gender identity have similar and different features of emotional attachment to their parents. 2. Characteristics of emotional attachment to the parents of children having violations in sex and age identification are typical for an earlier stage of the development. Characteristics of emotional attachment of children with an adequate age and gender identity are relevant to their age status. 3. Figure of the mother is the central object of attachment in preschool children.4. High emotional attachment of preschool children to the mother can lead to slowing and disrupting the process of maturation and may contribute to the formation of inadequate age and gender identity. 


\section{References}

Yershova, T.I. and B.E. Mikirtumov, 1995. Formation of biosocial system "mother-child" and its functioning in early childhood. Review of Psychiatry and Medical Psychology, 1: 55-63.

Bumpass, L.L. and R.K. Raley, 1995. Redefining single-parent families: Cohabitation and changing family reality. Demography, 32: $97-$ 109.

Crittenden, P.M., 1995. Attachment and psychopathology. In John Bowlby's attachment theory: his/hertorical, clinical, and social significance, Eds., Goldberg, S., R. Muir and J. Kerr, New York: The Analytic Press, pp: 367-406.

Crittenden, P.M. 1999. Danger and development: The organization of self-protective strategies. In Atypical attachment in infancy and early childhood among children at developmental risk, Eds., Vondra, J.I. and D. Barnett. Monographs of the Society for Research on Child Development. New York: Cambridge University Press, pp: 145-171.

Smirnova, E.O. and P.Radeva, 1999. Development of attachment theory (based on the works of P. Crittenden).Issues of Psychology, 1 : 105.

Kagan, V.E., 1991. Gender identity in children and adolescents in health and disease, thesis of a Doctor, Leningrad Pediatric Medical Institute, Leningrad.

Kon,I.S., 1999.Introduction to Sexology. Textbook for high school students. Moscow: Olymp, Infra-M, pp: 288.

Turner,K.L. and C.S.Brown, 2007. The importance of gender and ethnic identities across individuals and contexts. Social Development, 16: 700-719.

Brown,C.S., B.Alabi, V.Hyunh and C.Masten, 2011. Ethnicity and gender in late childhood and early adolescence: Group identity and awareness of bias. Developmental Psychology, 47: 463-471.

Burakova, M., 2000.Masculinity and femininity: the construction of the "real" men and women. Different view. International Almanac of gender studies. Minsk, pp: 18-21.

Abramenkova, V.V., 1987. Sexual differentiation and interpersonal relationships in the children's group. Issues of psychology, 5: 70-78.

Miklyaeva, A.V. and P.V.Rumyantseva, 2008. Social identity card: content, structure, mechanisms of formation: Monograph. St. Petersburg: Herzen State Pedagogical University of Russia Press, pp: 8-47.

Minullina, A.F. and I.A.Akramova, 2014.Characteristics of age and gender identity among children living in single-parent families. Education and self-development, 2(40):142-150.

Akramov, N.R., I.A.Akramova, A.K.Zakirov and A.F.Minullina, 2013. Gender identity as a basis for early surgical correction in children with violation of sex formation. Bulletin of modern clinical medicine, 6(Appendix 2):18-22.

Murtazina, E.I., A.F. Minullina and A.V.Frolova, 2014. Pedagogical Support Aimed to Form Future Pedagogue-Psychologists Readiness to Work with the Family. Middle-East Journal of Scientific Research, 20(8): 905-909.

Belopol'skaya, N.L., 2001. Age and sex identification: methodological studies of child identity. Moscow: Cognito-Center, pp: 24. 